Editorial

\title{
Religious Minorities and Struggle for Recognition
}

\author{
Christophe Monnot ${ }^{1,2, *}$ and Solange Lefebvre ${ }^{3}$ \\ 1 ISSR, University of Lausanne, 1015 Lausanne, Switzerland; E-Mail: christophe.monnot@unil.ch \\ 2 Faculty of Protestant Theology, University of Strasbourg, 67084 Strasbourg, France \\ ${ }^{3}$ Institute of Religious Studies, University of Montreal, Montreal, H3C 3J7, Canada; E-Mail: solange.lefebvre@umontreal.ca \\ * Corresponding author
}

Submitted: 5 August 2020 | Published: 20 August 2020

\begin{abstract}
Religious minorities are increasingly present in the public sphere. Often pointed out as a problem, we argue here that the establishment of these minorities in Western societies is happening through struggles for recognition. Communities or individuals belonging to different minorities are seeking recognition from the society in which they are living. In Section 1 , we present, briefly, our perspective, which differs from the analyses generally presented in the sociology of religion in that it adopts a bottom-up perspective. In Section 2, we present and discuss articles dealing with case studies in the cities of Barcelona, Geneva, and Montreal. In Section 3, we discuss two articles that present a process of individualization of claims for recognition. Finally, we present an article that discusses the case of an unrecognized minority in the Turkish school system.
\end{abstract}

\section{Keywords}

diaspora; governance; migration; minority; religious diversity; struggle for recognition

\section{Issue}

This editorial is part of the issue "Religious Minorities and Struggle for Recognition" edited by Christophe Monnot (University of Lausanne, Switzerland/University of Strasbourg, France) and Solange Lefebvre (University of Montreal, Canada).

(C) 2020 by the authors; licensee Cogitatio (Lisbon, Portugal). This article is licensed under a Creative Commons Attribution 4.0 International License (CC BY).

\section{A Bottom-Up Perspective}

The context of secular society and diversity in the 21st century presents new challenges. In the latter half of the 20th century, secularization relegated a portion of religiosity to the background of social issues. Then, the plurality of diversified populations from multiple origins resulted in a disturbing resurgence of religious issues. Mixed populations-consisting of a wide range of cultural and religious minorities with diverse demandsnow exist throughout Europe and other regions of the world, mainly in urban areas. Diversity is thus becoming "super-diversity" (Vertovec, 2007), with a multiplicity of factors that affect the space and lifestyle of citizens (Becci, Burchardt, \& Casanova, 2013).

Many individuals and communities are presently adopting new religious norms, spiritual practices, and dis- courses. Religious diversity has become clearly visible on a daily basis. In order to live appropriately, different minorities are also seeking recognition from the society in which they are living. Issues related to religion are increasingly present in the public sphere: For instance, religious or social actors easily use religious vocabulary instead of political or social vocabulary when putting forward claims for recognition. On one hand, sociologists of religion have documented numerous processes of religious diversification. We should note, for example, the studies of Kim Knott (2005) who explored the Hindu diaspora in British districts in regard to the opening of places of worship, but also the dynamic transformation this implies for the district with the establishment of clothing shops and Indian or vegetarian restaurants. However, in the sociology of religion, religious plurality has mainly been analyzed from the viewpoint of state regulation of religion. 
Instead of understanding diversity from a top-down perspective, namely regulation by political or public authorities, this volume proposes to look at the bottomup perspective, i.e., how and where communities are established, strategies of actors to make a place for themselves in society, and so on. More specifically, the goal of this volume was to gather contributions about two sets of issues; the first being the struggle for recognition by actors/communities belonging to religious diversity, while the second involves issues about the contexts in which claims are put forward. Interestingly, we received three articles explicitly related to urban settings, and three others examine respectively differences between generations, the way marginalized groups are using social networks to affirm themselves, and the struggle of an ethnoreligious minority to be recognized in the public school system.

\section{The City Where New Struggles for Recognition Emerge}

The three contributions related to the city complement and respond to each other in an interesting way. Julia Martínez-Ariño (2020) argues that spatial practices of contemporary Jewish organizations in Barcelona's medieval Jewish neighborhood represent claims for public recognition. These Jewish organizations claim their presence in the medieval Jewish neighborhood of the city through a series of spatial practices, mainly heritage production, renaming of streets, and temporary marking of spaces with Jewish symbols. For the author, this constitutes a strategy of "place-recovering" (Martínez-Ariño, 2020), a creative process by which historical narratives and past myths play a crucial role in gaining visibility and obtaining recognition of Jews, a small and rather invisible minority.

Solange Lefebvre (2020) asserts that spatial dimension is a key aspect to understand tension with religious minority communities. The author analyzes the decisionmaking process resulting in a failure to modify zoning regulations in order to welcome new places of worship in a borough of Montreal. She shows how, in the City of Montreal, a few actors are exploiting provincial regulations in order to oppose public decisions seeking to establish new spaces for Muslim minorities, such as cemeteries or prayer rooms, using a process for approving amendments to zoning bylaws by way of a referendum. While analyzing administrative and legal aspects, the author exposes the complexity of the social and spatial dynamics at play. She brings attention to the perverse effect of some local participatory procedures, whereby a few actors maneuver to mobilize citizens, in order to resist religious pluralization of space. Martínez-Ariño (2020) and Lefebvre (2020), in their respective research about Jews in Barcelona and Muslims in Montreal, reflect on problems encountered by religious minorities when it comes to finding a place or space in the city, while documenting the various actors' perceptions and uses of these places and spaces.
Christophe Monnot (2020) shows that in a specific city, past responses to the emergence of the "first" instance of diversity determine the path for current regulation of religious diversity. From the history of Geneva, he contends that top-down regulation of religion responds to one or more bottom-up strategies of religious communities to find legitimacy in a constraining environment. This historical perspective provides the consistency of current governance of religious diversity, illuminating the struggle for recognition of minority groups. The article, studying the case of Geneva, complements the one by Lefebvre (2020). Both show the process of interaction between claims by minorities, regional regulations, and diverse strategies of local actors that favor or block sustainable diversity, with each of them maneuvering in very complex ways in relation to the legal regimes in place.

From a theoretical angle, this section presents rich perspectives, helping to reflect on diverse locations, spaces, and the way individuals and groups belonging to minorities are competing to regain, share, get a piece of those spaces and places, feel welcome, and be fully recognized despite their minority status, culture, and practices. It also explores the ways in which so-called majorities and well-established minorities structure their responses to those needs through regulations and negotiation strategies, showing that a variety of actors are interacting with conflicting visions of shared spaces. The Jewish group's strategies for recognition in Barcelona are executed through several "spatial practices" in the medieval Jewish neighborhood. While spatial dimensions rarely constitute an analytical category, this aspect is nevertheless a continual source of tension in relation to religious diversity, as the case of Muslims in Montreal demonstrates with obstacles faced relating to claims for Muslim cemeteries and places of worship. The historical perspective has to be taken into account in order to understand how past responses to diversity are still shaping contemporary decisions, as the case of Geneva specifically highlights.

\section{Claims for Recognition as Individual Beings}

In the next section, two contributions draw attention to how young people from religious minorities use different strategies to assert their groups' particularities. First, Martin Baumann and Rebekka Christine Khaliefi offer a comparative analysis of two generations of Buddhists and Muslims in Switzerland, showing how the greater importance of the individual among young people modifies these strategies and the relationship with public space (Baumann \& Khaliefi, 2020). In Switzerland, immigrant minorities have established cultural and religious associations to maintain cultural and religious traditions from their country of origin. In contrast to the first immigrant generation, the second generation has had concurrent social influences from the regular Swiss school system and the cultural-religious traditions of 
their parents. The authors argue that not only are outward changes of religiosity observable among secondgeneration youths, but also that despite an intensified degree of individualization, some of their newly founded youth associations are struggling for social recognition through civic engagement.

Second, Rodríguez-Puertas and Ainz-Galende (2020) have been researching a private Telegram channel for young women who wear the full Islamic veil in hostile Western environments, and the way they support each other to reinforce and assert the deep meaning of their choice to do this, insisting on freedom and individuality. Having overcome the difficult access to these women and their discourses, the authors analyze how demands are articulated through the channel, and how actions are organized. They show that these are mainly related to a claim for recognition as autonomous and political individuals, who are connected virtually through a social network.

The theoretical perspective of Baumann and Khaliefi (2020) provides an insightful reading of generational differences within a specific minority, showing notably that associative strategies of youth are more individual. Religious claims take a back seat, and it is civic engagement that takes precedence in the second generation of religious minority immigrants in Switzerland. This observation responds to Rodríguez-Puertas and Ainz-Galende (2020), who also observe a claim as individual and political beings from women wearing the full Islamic veil, done through a private channel that creates new forms of community and claims for recognition.

\section{What About a Despised Minority?}

Lastly, an article by Sakız, Ekinci, and Baş (2020) explores the feeling of parents and pupils, excluded from the school environment, as they are members of an ancient Syriac Christian minority. It critically addresses public policies of inclusion being limited to individuals with disabilities and a few officially recognized minorities. Through their study of the way parents and pupils from an ethnoreligious minority feel in their public-school environment in Turkey, the authors show how multiculturalism is inspiring a growing number of people to affirm their specific culture, despite historical resistance. They underline the key role of the educational system in this process. They emphasize the importance of schools around the world taking into consideration increasingly diverse school populations, with a particular focus on cultural and religious diversity.

\section{Acknowledgments}

The editors are grateful to Liane Grant for her editorial assistance and linguistic revisions.

\section{Conflict of Interests}

The authors declare no conflict of interests.

\section{References}

Ainz-Galende, A., \& Rodríguez-Puertas, R. (2020). The demands of Niqabi women in the Telegram subaltern corner Orgullo Niqabi. Social Inclusion, 8(3), 286-295. http://dx.doi.org/10.17645/si.v8i3.3033

Baumann, M., \& Khaliefi, R. C. (2020). Muslim and Buddhist youths in Switzerland: Individualising religion and striving for recognition? Social Inclusion, 8(3), 273-285. http://dx.doi.org/10.17645/si.v8i3.3071

Becci, I., Burchardt, M., \& Casanova, J. (2013). Topographies of faith: Religion in urban spaces. International studies in religion and society. Leiden: Brill.

Knott, K. (2005). The location of religion: A spatial analysis. London: Equinox.

Lefebvre, S. (2020). Space, religious diversity, and negotiation processes. Social Inclusion, 8(3), 251-261. http://dx.doi.org/10.17645/si.v8i3.3260

Martínez-Ariño, J. (2020). Jewish spatial practices in Barcelona as claims for recognition. Social Inclusion, 8(3), 240-250. http://dx.doi.org/10.17645/si. v8i3.3012

Monnot, C. (2020). The city as a continuous laboratory for diversity: The case of Geneva. Social Inclusion, 8(3), 262-272. http://dx.doi.org/10.17645/ si.v8i3.3057

Sakız, H., Ekinci, A., \& Güldest, B. (2020). Inclusive education for religious minorities: The Syriacs in Turkey. Social Inclusion, 8(3), 296-306. http://dx.doi.org/ 10.17645/si.v8i3.3073

Vertovec, S. (2007). Super-diversity and its Implications. Ethnic and Racial Studies, 30(6), 1024-1054. https:// doi.org/10.1080/01419870701599465

\section{About the Authors}

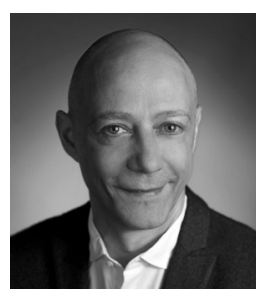

Christophe Monnot is Assistant Professor of Sociology of Religion at the University of Strasbourg and SNF Senior Researcher at the University of Lausanne. His research focuses on congregations in context. $\mathrm{He}$ is the author of many articles in leading journals like Social Compass (awarded in 2008 for the best article), Journal of Religions in Europe, and Journal of Contemporary Religions. He has edited several books in French and in English, such as Congregations in Europe (Springer, 2018, with J. Stolz). 


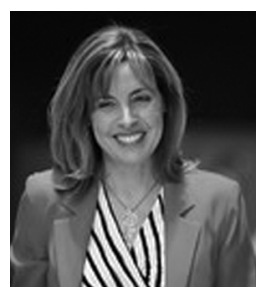

Solange Lefebvre is a Full Professor at the Institute of Religious Studies, University of Montréal. She holds the Research Chair in Management of Cultural and Religious Diversity and has been named Director of a Research Center on Religions and Spiritualities (CIRRES). Her areas of interest include religion in the public sphere, secularism and secularisation, youth, and generations. Among her recent publications are included: Annual Review of the Sociology of Religion 9: The Changing Faces of Catholicism (Brill, 2018); Public Commissions on Diversity (Routledge, 2017); Catholicisme et cultures: Regards Croisés Québec-France [Catholicism and Cultures: Converging Views of Québec-France; PUR, 2015). 